\title{
Analysis of Types and Causes of Traumatic Dental Injuries to Permanent Dentition among Patients Attending Tertiary Care Hospital of Pakistan
}

\author{
Mahwish Memon*, Mowaffaq Abdullmomen Al Absi, Zahid Hussain Siyal, Anny Memon, \\ Abdul Ghani Shaikh
}

Liaquat University of Medical and Health Sciences, Jamshoro, Pakistan

Email: ${ }^{\star}$ dentist_memon@hotmail.com

How to cite this paper: Memon, M., Al Absi, M.A., Siyal, Z.H., Memon, A. and Shaikh, A.G. (2020) Analysis of Types and Causes of Traumatic Dental Injuries to Permanent Dentition among Patients Attending Tertiary Care Hospital of Pakistan. Open Journal of Stomatology, 10, 211-217. https://doi.org/10.4236/ojst.2020.108020

Received: July 1, 2020

Accepted: July 31, 2020

Published: August 3, 2020

Copyright $\odot 2020$ by author(s) and Scientific Research Publishing Inc. This work is licensed under the Creative Commons Attribution International License (CC BY 4.0).

http://creativecommons.org/licenses/by/4.0/

\begin{abstract}
Objective: This study aimed to evaluate the age, gender, causes, place of trauma, and type of crown fracture in permanent dentition among patients attending Liaquat University of Medical and Health Sciences Hospital (LUMHS), Jamshoro, Pakistan. Methodology: This cross-sectional study was conducted at the Operative Dentistry Department of LUMHS hospital over a period of six months. All patients (6 - 40 years of age) who had a history of dental trauma and attending dental OPD were included in this study. The data for all patients were recorded in a predesigned proforma. Data were collected on age, gender, place of trauma (playground, road, home), cause of trauma (fall, playing, road accident, bicycle accident, collisions, fighting) and associated symptoms. The data were analyzed using SPSS 22.0. Mean and the standard deviation was computed for a quantitative variable like age. Frequency and percentage were calculated for qualitative variables like gender, risk factors, and pattern of trauma. Results: A total of 82 patients were enrolled. The most frequent age group involved was 13 - 20 years (46\%) with males (58.5\%) predominance. The majority of trauma cases were due to fall $(36.6 \%)$ while playing and $19.5 \%$ were bicycle accidents. The most commonly affected tooth was right maxillary central incisor (46.6\%) followed by left maxillary central incisor (28.4\%). Of the 116 teeth examined, 56.0\% had a complicated crown fracture and $44.0 \%$ had an uncomplicated crown fracture. Conclusion: Safety measures should be implemented where dental traumatic accidents occur most frequently like at home and on the roads.
\end{abstract}

\section{Keywords}

Dental Trauma, Crown Fracture, Fall, Public Safety 


\section{Introduction}

Orofacial trauma is among the most prominent oral health problems affecting children in developing countries [1]. While diseases such as dental caries and periodontal disease have been given due importance and are still considered to be the most significant oral health problems worldwide, trauma to the anterior teeth with the underlying aesthetic, psychosocial, functional, and therapeutic problems adversely affect an individual's quality of life [2].

Dental trauma is a major health problem in many societies, with higher prevalence rates among children and adolescents [3] [4] [5]. Demographic evaluations indicate a higher prevalence of trauma in males compared to females. Falling, fight, sports, accidents, and hitting items or people are among common etiological factors [6]. The home setting, school, and street are places with the highest frequency of dental traumatic injuries, which most importantly include enamel fracture and enamel and dentin fracture without pulp exposure [6].

An individual's quality of life is strongly influenced by their health condition. In the field of dental health, physical constraints may directly influence aspects of feeding, speech, social interaction and self-esteem, and psychology [7]. It is accepted that the position and appearance of the anterior teeth have a psychological and social impact on children [8]. Therefore, it is not surprising that dental problems are linked to social and psychological and emotional well-being. The contribution of dentofacial characteristics to dimensions of personality, self-esteem, and body image is well documented [2].

\section{Methodology}

The objective of this study was to evaluate the age, gender, causes, place of trau$\mathrm{ma}$, and type of crown fracture. The study design was cross-sectional. The sample size was 82 and the sampling technique was non-probability consecutive sampling. This study was conducted at the Institute of dentistry LUMHS. Patients referred to the Dentistry Department for the treatment of traumatic dental injuries over a period of six months from July 2019 to December 2019 were included in this study. Ethical review committee of LUMHS approved this study.

Inclusion criteria:

1) All patients with a history of trauma attending dental OPD;

2) Permanent dentition (age 6 years to 40 );

3) Clinical examination showed a crown fracture.

\section{Exclusion criteria:}

1) Primary dentition;

2) Luxation injuries.

The data for all patients were recorded in a predesigned proforma. Patients history was taken about age, gender, place of trauma (playground, road, home,) cause of trauma (fall, playing, road accident, bicycle accident, collisions, fighting). Informed consent was obtained from all patients examined clinically by the Principal investigator. 
On clinical examination, data regarding the type of trauma categorized according to WHO classification, the number of teeth, type of tooth, tooth color, sensitivity or pain, presence of swelling and sinus track, and possible displacement. The data was analyzed using SPSS 22.0. Mean and the standard deviation was computed for a quantitative variable like age. Frequency and percentage were calculated for qualitative variables like gender, risk factors, and pattern of trauma.

\section{Results}

The total sample consists of 82 patients that were referred to the Operative Dentistry Department of Liaquat University Hospital over a period of five months. The total number of teeth examined was 116 . Out of 82 patients, $46 \%$ belong to the age group of $13-20,28 \%$ of patients fall in the age group of $6-12$, and $11 \%$ belong to the age group of $21-30$ and the remaining above 31 years (Figure 1). Regarding gender, $58.5 \%$ were males (Table 1 ). The mean age was 17.6 years (SD \pm 8.32). See Table 2 .

Regarding location in the present study, $31.7 \%$ had dental traumatic injuries at home and $30.5 \%$ suffered road traffic accidents, $18.3 \%$ suffered injuries at school, and $17.1 \%$ at playgrounds (Figure 2).

From 82 patients with dental trauma, $36.6 \%$ suffered trauma due to fall while playing and $19.5 \%$ due to bicycle accidents, $19.5 \%$ fall due to slippage, and others due to a road traffic accident and contact with a hard surface (Figure 3 ).

The most commonly affected tooth was right maxillary central incisor (46.6\%) and followed by left maxillary central incisor in $28.4 \%$ of cases (Figure 4 ). Of the

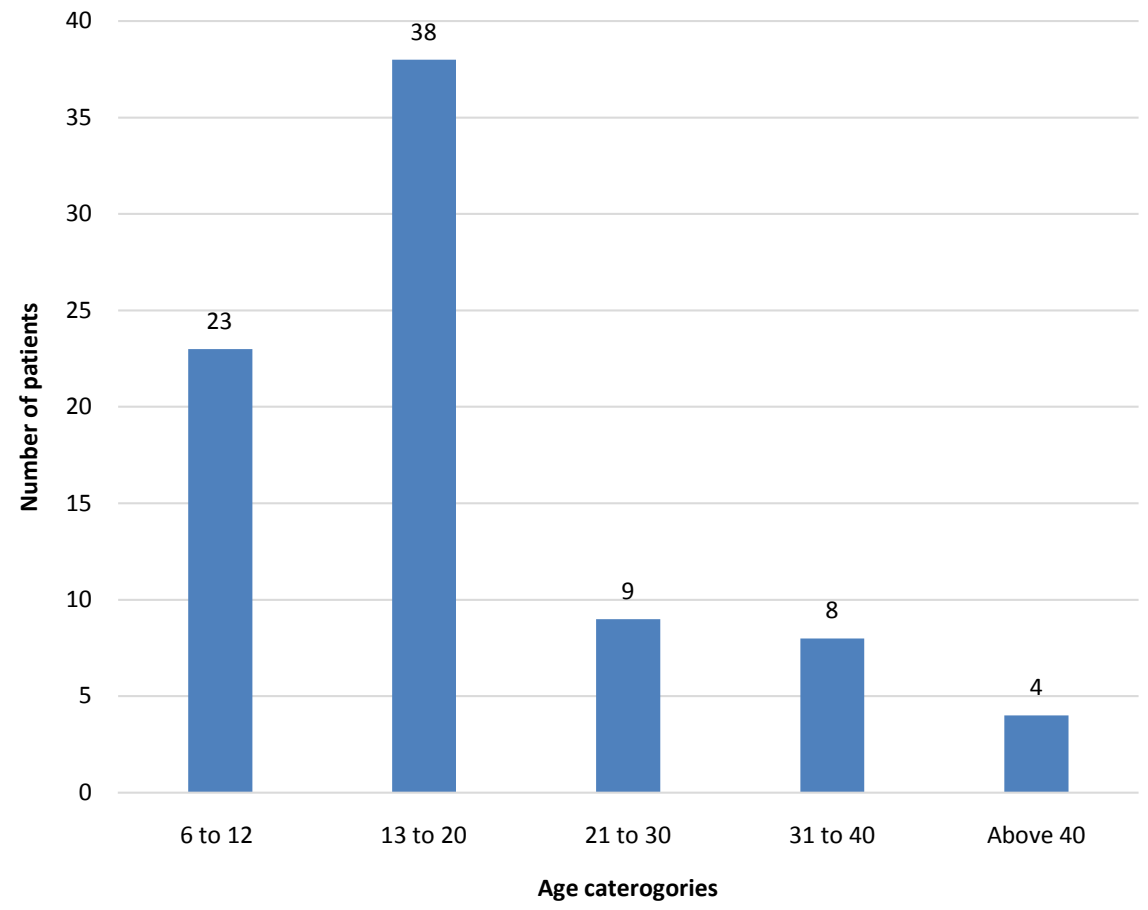

Figure 1. Age distribution of patients. 
Table 1. Gender distribution.

\begin{tabular}{ccc}
\hline & $\mathrm{N}$ & $\%$ \\
\hline Male & 48 & 58.5 \\
Female & 34 & 41.5 \\
Total & 82 & \\
\hline
\end{tabular}

Table 2. Types of fracture.

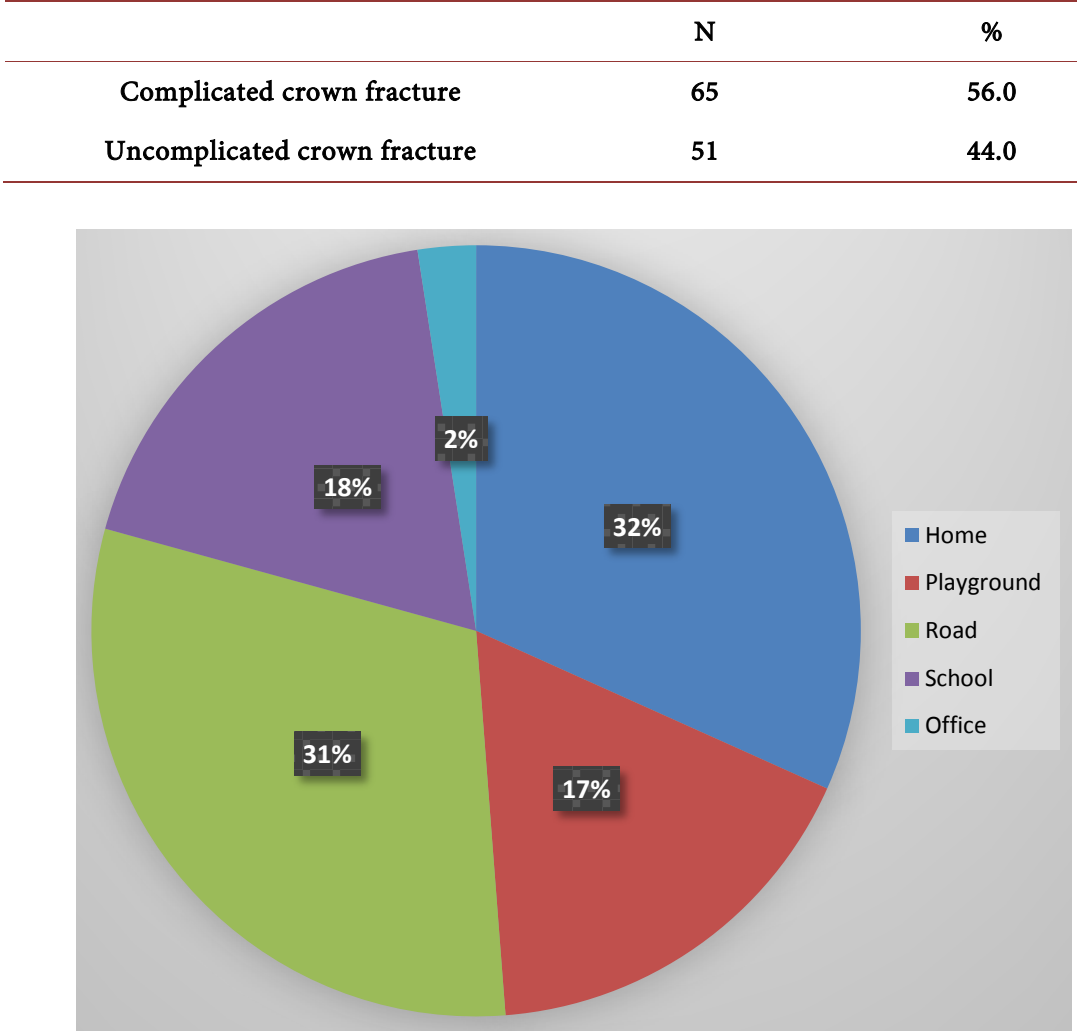

Figure 2. Pie chart showing trauma location (\%).

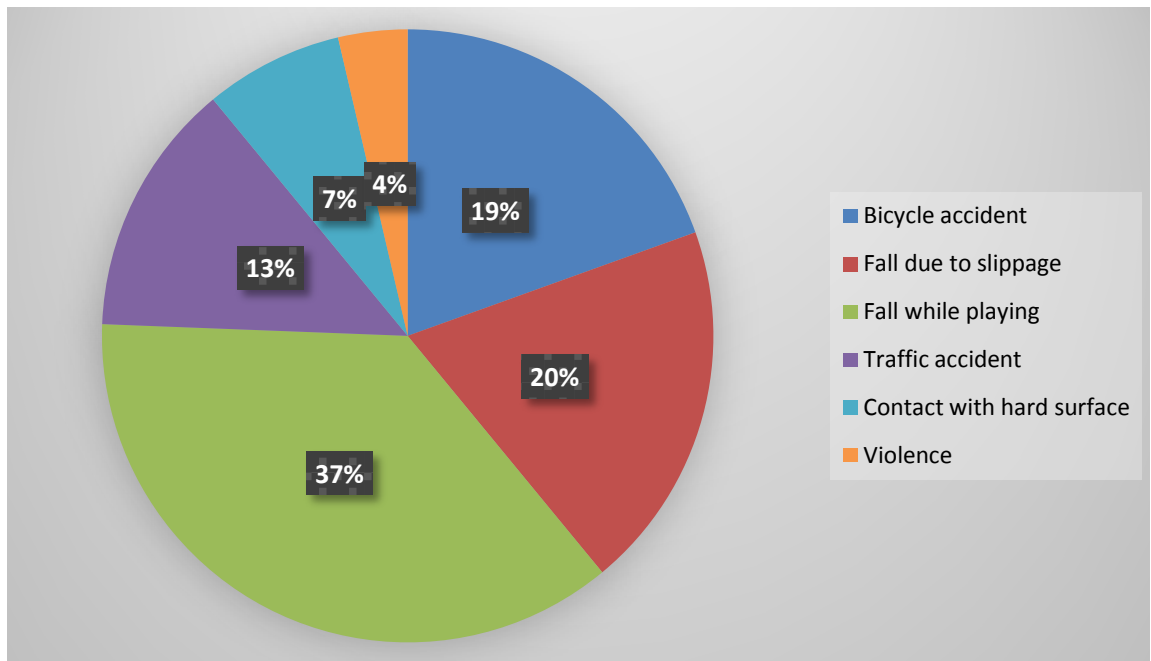

Figure 3. Pie chart showing causes of trauma (\%). 


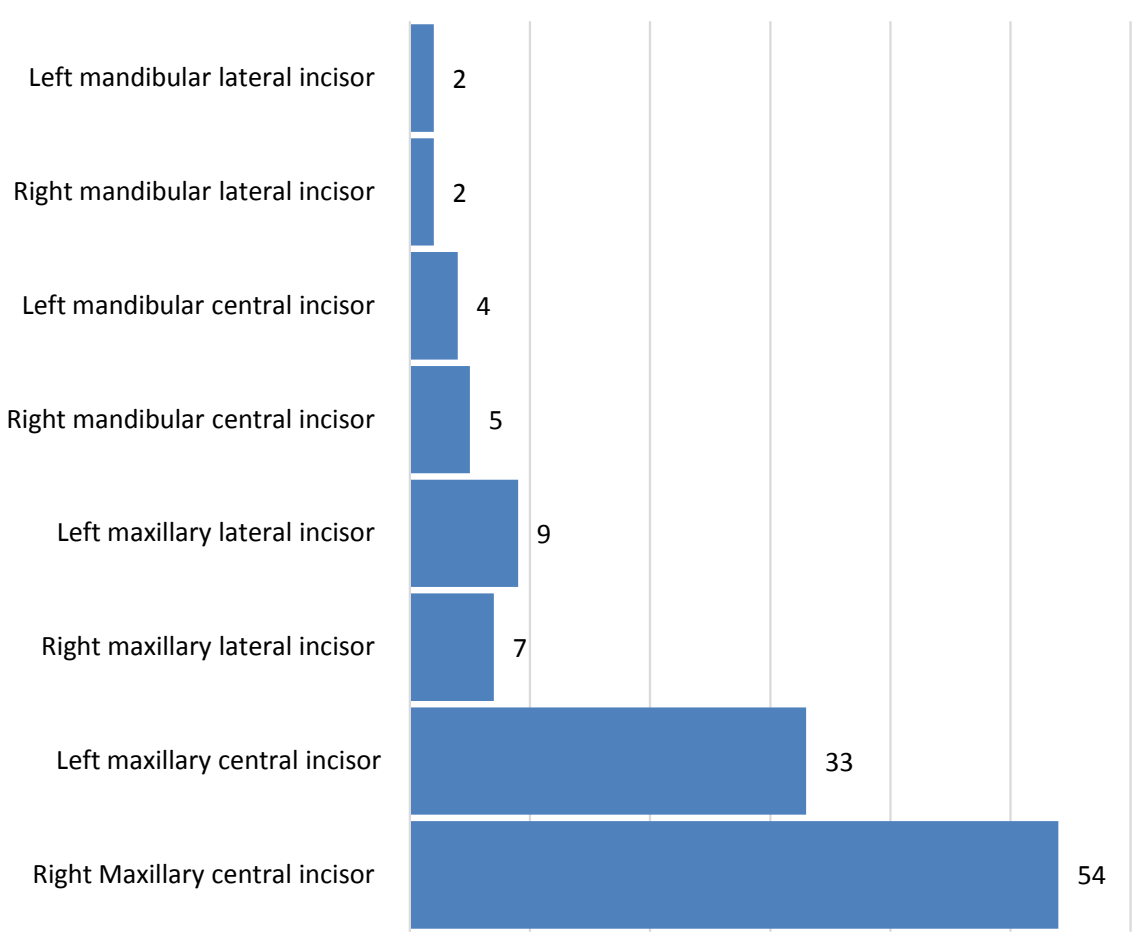

Figure 4. Barchart showing distribution of affected teeth.

116 teeth examined, $56 \%$ had a complicated crown fracture and $44 \%$ had an uncomplicated crown fracture (Table 2).

Out of 116 teeth, $74.1 \%$ of cases had complications of pain on hot and cold and on biting, swelling, sinus tract, and slight displacement of teeth, while, $25.8 \%$ had no symptoms and only concerned about esthetics.

\section{Discussion}

The study findings concluded that traumatic injuries were more common in the age group of 13 to 20 years followed by $6-12$ years old. This is in agreement with a study conducted by Saima $\mathrm{R}$ et al. [9] but in most studies, it is more common in the age group of 9 to 12 years [10]. This could be due to the fact that most of the studies were conducted on children aged $6-12$ years.

This study found more prevalence in males than females. This was in agreement with most of the previous studies [10]. This could be because males are more involved in sports, outdoor activities, road traffic accidents, and violence with a higher risk of traumatic dental injuries and girls are less involved and stay indoors because of cultural set up in Pakistan.

Location for dental traumatic injuries was at home followed by road accidents. This is in accordance with another study conducted by Soriano EP in Brazil [11].

In this study, the main reported the most common cause of dental injuries was fall while playing and falls due to slippage. This is in agreement with the results of Trumen EC et al. [10]. This study also found some cases of falls due to fainting due to Pakistan's extremely hot weather conditions. 
The finding of the present study demonstrates that the most commonly affected tooth was maxillary right central incisor followed by maxillary left central incisor. This is in agreement with Ilyas $\mathrm{M}$ et al. [12]. Maxillary central incisors are commonly involved in dental traumatic injuries may be because of their prominent and vulnerable position in a dental arch.

This study found the most frequent type of dental traumatic injuries were complicated crown fracture involving the enamel, dentin, and pulp involvement followed by uncomplicated crown fracture. This is in contrast to most of the studies which have reported uncomplicated crown fracture involving enamel and dentin without pulp involvement [13] [14].

It is likely these teeth may not have developed signs and symptoms of pulpal involvement, so these are underreported and so don't require or seek dental care.

\section{Conclusions}

It is concluded from the present study that the most commonly involved tooth was maxillary right central incisor and the most frequent type of dental traumatic injuries was a complicated crown fracture. The most frequent cause was falling and the most common location was home followed by road accidents.

Traumatic dental injuries are recognized as public dental health problems worldwide, that require adequate planning and interventions to prevent their occurrence. Safety measures should be implemented where dental traumatic accidents occur most frequently like at home and on roads.

\section{Consent for Publication}

Not applicable.

\section{Availability of Data and Material}

Not applicable.

\section{Funding}

The study was self-funded by Dr. Mahwish Memon.

\section{Authors' Contributions}

MM and SA contributed to drafting the article. MM, MA, ZS and AM collected the data in the hospital. MM and GS managed and analyzed data. MM and MA designed and supervised the study. All authors approved the final version of the article for submission.

\section{Acknowledgements}

We would like to acknowledge all patients for providing us time and data for this study. We would also like to thank all our support staff in conducting this study. 


\section{Conflicts of Interest}

The authors declare that they have no competing interests.

\section{References}

[1] World Health Organization (2008) Oral Health. https://www.who.int/news-room/fact-sheets/detail/oral-health

[2] Andreasen, J.O., Andreasen, F.M. and Andersson, L. (2018) Textbook and Color Atlas of Traumatic Injuries to the Teeth. 5th Edition, Wiley-Blackwell, Hoboken.

[3] Martins, V.M., Sousa, R.V., Rocha, E.S., Leite, R.B., Paiva, S.M. and Granville-Garcia, A.F. (2012) Dental Trauma among Brazilian Schoolchildren: Prevalence, Treatment and Associated Factors. European Archives of Paediatric Dentistry, 13, 232-237. https://doi.org/10.1007/BF03262876

[4] Kovacs, M., Pacurar, M., Petcu, B .and Bukhari, C. (2012) Prevalence of Traumatic Dental Injuries in Children Who Attended Two Dental Clinics in Targu Mures between 2003 and 2011. Oral Health and Dental Management, 11, 116-124.

[5] Piovesan, C., Abella, C. and Ardenghi, T.M. (2011) Child Oral Health-Related Quality of Life and Socioeconomic Factors Associated with Traumatic Dental Injuries in Schoolchildren. Oral Health and Preventive Dentistry, 9, 405-411.

[6] Saber, A., Farbood, E. and Fatemah, P. (2015) Prevelance, Etiology, and Types of Dental Trauma in Children and Adolescents: Systematic Review and Meta-Analysis. Medical Journal of the Islamic Republic of Iran, 29, 234.

[7] Traebert, J., Lacerda, J.T., Foster Page, L.A., Thomson, W.M. and Bortoluzzi, M.C. (2012) Impact of Traumatic Dental Injuries on the Quality of Life of Schoolchildren. Dental Traumatology, 28, 423-428. https://doi.org/10.1111/j.1600-9657.2012.01114.x

[8] Cortes, M.I., Marcenes, W. and Sheiham, A. (2002) Impact of Traumatic Injuries to the Permanent Teeth on the Oral Health-Related Quality of Life in 12-14-Year-Old Children. Community Dentistry and Oral Epidemiology, 30, 193-198. https://doi.org/10.1034/j.1600-0528.2002.300305.x

[9] Saima, R., Moeen, A. and Amatul, R. (2012) Etiology, Pattern and Associated Features of Traumatic Tooth Fractures. Pakistan Oral and Dental Journal, 32, 522-525.

[10] Tumen, E.C., Yavuz, I., Kaya, S., Uysal, E., Tumen, D.S., Ay, Y., et al. (2017) Prevalence of Traumatic Dental Injuries and Associated Factors among 8 to 12-Years-Old Schoolchildren in Diyarbakir, Turkey. Nigerian Journal of Clinical Practice, 20, 1259-1266. https://doi.org/10.4103/1119-3077.219518

[11] Soriano, E.P., Caldas Ade Jr., F., Diniz De Carvalho, M.V. and Amorim Filho Hde, A. (2007) Prevalence and Risk Factors Related to Traumatic Dental Injuries in Brazilian Schoolchildren. Dental Traumatology, 23, 232-240. https://doi.org/10.1111/j.1600-9657.2005.00426.x

[12] Ilyas, M., Shah, S.M.A., Khattak, M.S.K. and Kundi, J.A. (2017) Pattern and Causes of Traumatic Injuries to Permanent Teeth in Children of Age 7 to 14 Years. Biomedica, 33, 296-299.

[13] Ekanayake, L. and Perera, M. (2008) Pattern of Traumatic Dental Injuries in Children Attending the University Dental Hospital, Sri Lanka. Dental Traumatology, 24, 471-474. https://doi.org/10.1111/j.1600-9657.2008.00611.x

[14] Diaz, J.A., Bustos, L., Brandt, A.C. andFernandez, B.E. (2010) Dental Injuries among Children and Adolescents Aged 1-15 Years Attending to Public Hospital in Temuco, Chile. Dental Traumatology, 26, 254-261. https://doi.org/10.1111/j.1600-9657.2010.00878.x 